\title{
Structural change from physical foundations: The role of the environment in enacting school change
}

\author{
Pamela Woolner ${ }^{1}$ (D) Ulrike Thomas ${ }^{1} \cdot$ Lucy Tiplady $^{1}$
}

Published online: 3 February 2018

(C) The Author(s) 2018. This article is an open access publication

\begin{abstract}
Educational change is known to be challenging and therefore research exploring the conditions that seem to facilitate change is important. The literature relating to school level change shows some awareness of the part played by the physical school environment, but the role of the school premises in change is rarely the focus of research rooted within this literature. This is a notable omission. The history of innovation in school design parallels the recognised challenges of school reform and change. Educational leadership practice and certain historic policy initiatives suggest awareness of how the physical environment may encourage or constrain, and so is potentially an important part of a change process, but this understanding is not developed. This paper brings together our research concerning school environments and our work with schools attempting pedagogical change to develop such an understanding of the place of the physical setting in initiating, supporting and sustaining school level change. It is a conceptual exploration of the role of the physical environment in enacting change using an empirical base to illustrate our argument. We present a narrative account of two schools' approaches to change and use the theoretical framework of culture, structure and individual action, where the physical environment is part of the structure within which change is attempted. It becomes clear that although the physical setting is intimately related to other school structures, particularly certain organisational features, there is a qualitative difference in the way the physical setting, as a tangible and visible entity, contributes to change processes. As well as contributing to the development of conceptualisations of educational change, our exploration has implications for the wider understanding of structures within human society, and their relationship to culture and individual agency.
\end{abstract}

Pamela Woolner

pamela.woolner@ncl.ac.uk

1 School of ECLS, King George VIth Building, Newcastle University, Newcastle NE1 7RU, UK 
Keywords Agency $\cdot$ Culture $\cdot$ Curriculum $\cdot$ Learning environment $\cdot$ School space $\cdot$ Structure $\cdot$ Innovation

\section{Introduction}

\section{Change in schools}

Educational change is known to be challenging (see e.g. Elmore 2016; Fullan 2007; Tyack and Tobin 1994). There is an extensive research literature relating to school level change, both policy led (e.g. Priestley 2011; Hargreaves 2002) and driven by within-school initiatives (e.g. Ouston et al. 1991; Thomson et al. 2009). The consistent finding is that change is hard, time-consuming and frequently fails to occur: the "paradox of innovation without change" (Priestley et al. 2011, p. 266). As Thomson concludes from her review of the research in this area: "Whole school change is elusive in practice and in the literatures" (Thomson 2007, p. 10).

Various conceptions of school organisation and change processes have been proposed to explain observed events and to guide school leaders and others in enacting successful change, but these tend to be practical and descriptive, as opposed to comprehensively theorised. Of particular note is the work of Fullan who has charted successful school reform and proposed three necessary elements: being embedded in school structures, having a critical mass of school staff trained and committed, and having a procedure for continued support (Fullan 2007, p. 102). Fullan also draws attention to the stages of change (initiation, implementation and institutionalisation), thus providing a useful way to examine change in progress. However, there is considerably less conceptual clarity with respect to explaining why and how change attempts succeed or fail.

Relating to Fullan's observation about training and the commitment of a critical mass of staff when undertaking reform, educationalists have also noted the importance of practitioner action as opposed to only a policy-level instruction, and much has been written about the relationship between policy and practice (e.g. Hargreaves 2002; Pollard 1985). Specifically, having contributed a seminal study of school level change (Ball 1981) and a useful discussion of the nature of policy (Ball 1993), Stephen Ball has, with colleagues, gone on to study the "enactment, rather than implementation" (Maguire et al. 2015, p. 487) of policy by the diverse body of actors within each of a heterogeneous range of schools. Similarly, Priestley argues that we need to move beyond a dichotomy of policy and practice, as this encourages a simplistic view of policy as "something monolithic" (Priestley 2011, p. 6) and tends through its unexamined assumption of individual agency to position teachers as either "barriers" or "agents of change" (Priestley 2011, p. 2; see also, Ball 1993, p. 13 for a dismissal of 'resistance' as "crude and over-used"). Priestley argues for the need to understand the detail of the situation in sociological terms, and his framework of culture, structure and individual action draws particularly on the work of Archer (2000). The resulting conceptualisation, he proposes, "allows us to disentangle the various aspects that contribute to the unfolding of a given social 
situation, enabling us to make judgements about the relative causative weight of culture, structure and agency" (Priestley 2011, p. 7).

In this paper we have adopted the framework proposed by Priestley to examine some examples of attempted change that involved alterations to the physical school setting. Using this framework enables us to understand better situations where educational change is centred on the physical setting, which, as we will first discuss, has proved difficult to understand in the past. In addition, we will argue that the application of this framework to the physical and social situation of 'a school' highlights aspects of the foundational ideas that are sometimes overlooked in their more standard sociological applications. In particular, following Priestley (2011, p. 5), we are including aspects of the physical setting within our examination of structure in school. This raises some issues in that sociologists tend to focus on non-physical aspects of social structures while Priestley and colleagues (e.g. Biesta et al. 2015) have sometimes separated the 'material' from the 'structural' aspects of teachers' contexts. These ways of treating human systems suggests that there may be some theoretical incoherence in running together elements such as classroom furnishings which are unproblematically embodied in space and time with less tangible structures such as staff hierarchies. However, it is worth noting that the 'spatial turn' in geography (Massey 2005) proposes a fundamental social side to physical space, "the production of space through the interaction of the physical and the social" (McGregor 2004a, p. 3). A recently published methodological contribution argues for the importance of researchers in education taking a 'place-based' approach where each school is viewed as a physically located site for social interactions (Thomson and Hall 2016) and the application of spatiality to school settings continues to prove enlightening (e.g. Mulcahy et al. 2015; McGregor 2004b; Nespor 2002). Thus a body of work within and beyond education research would tend to support our decision to include the range of social to material resources within our conceptualisation of structure. Through examining why this makes sense within the educational context, we hope to contribute to the wider conceptualisation of the functioning of human systems alongside our main intention of using these understandings to demonstrate the particular contribution of the physical environment to educational change.

\section{Physical space, education and change}

First it is necessary to introduce some background ideas about the physical learning environment. As has been discussed elsewhere by a number of scholars, the evidence base relating to the absolute impact of the physical setting on learning is complex (Gislason 2010; Woolner et al. 2007; Weinstein 1979). Although the physical environment does not determine educational activities, there is evidence of a relationship between school setting and the activities that take place there (HorneMartin 1999, 2002) and research tends to suggest that different settings facilitate some pedagogical and social practices while hindering others. For example, in schools that consist of cellular classrooms where student desks are organised to face the front, there tends to be a more teacher- centred approach to learning with less 
student collaboration (Sigurðardóttir and Hjartarson 2011). This relationship of the school environment to practices has suggested to some educators and school leaders that changing the physical setting is an effective way of initiating or supporting change (e.g. Saltmarsh et al. 2015; Mulcahy et al. 2015; Briggs 2001). Yet the results of such environmentally-led change are mixed. Sometimes changes to the physical setting facilitate other developments (Uline et al. 2009), but the evidence would also suggest that classroom space can be changed quite dramatically without much resulting change in pedagogical practices (Bennett et al. 1980).

If we accept that innovation linked to physical school space sometimes demonstrates Priestley's 'paradox of innovation without change', while on other occasions it seems to be supportive or even catalytic it seems important to try and understand how these different outcomes occur. And yet, current school change research literature tends not to focus on the role of the school premises in enacting change, despite the fact that some shows an awareness of the influence of the physical school environment. Priestley, for example, reports a case where the layout of classrooms facilitated the interaction of two key teachers. He comments that pedagogical practices are "often a practical response to the spatial characteristics of the school" (2011, p. 14), but this aspect is not further developed. Similarly, Maguire and colleagues note material constraints and affordances, the "grounded factors of time and place" (Maguire et al. 2015, p. 487) and include the observation that "policy enactments are also more/less visible depending on where the departments and staff are physically located in the school campus" (Maguire et al. 2015 , p. 494). These ideas are not as well researched or developed, however, as the actions and understandings of human actors within the school environment.

In contrast, some studies where the focus is more concertedly on the school setting (e.g. Frelin and Grannäs 2014; Gislason 2015) may report the results of change or improvement, but with less explanation attempted of how the change was enacted. In fact, review work has concluded that research specifically focused on the educational setting from both educational and architectural perspectives has tended to concentrate on the proposed products of the environment as opposed to the process: "how schools prepare for, and transition into, new learning spaces in ways that encourage innovative pedagogical practices" (Blackmore et al. 2010, p. 12; see also Blackmore et al. 2011). That this is changing is suggested by a number of researchers now exploring the evolution of teaching and learning practices in altered settings (e.g. Imms and Byers 2017; Saltmarsh et al. 2015; Campbell et al. 2013; Alterator and Deed 2013) and proposing new ways to understand the dynamic relationship between educational space and activities (e.g. Cleveland and Fisher 2014; Dovey and Fisher 2014; Boys 2011). It is our intention that this paper will contribute to this growing body of work, whilst also enabling us to develop further our conceptualisation of the role of the physical environment in change.

We will first consider the potential of the physical school environment in setting change in motion (initiation, in Fullan's terms). Then, acknowledging the importance and difficulty of getting beyond this stage, we investigate how physical settings can support and sustain change. We do this through reconsidering, in relation to initiating change, some of our experiences and observations from previous research projects, the methodologies and results of which have previously 
been reported (McCarter and Woolner 2011; Woolner et al. 2012a, b, 2014). We then present narrative accounts of attempted change from two UK schools that have participated in research projects with us (see Woolner and Tiplady 2016; Leat and Thomas 2017) using Priestley's framework in order to examine the role of structure, culture and individual action. We conclude by exploring what these applications reveal about this particular conceptualisation and for wider issues in the theorising of change.

\section{Physical space as the initiator of change}

The benefits of reflection on practice are well established. In education and beyond, being a 'reflective practitioner' is recognised as desirable (Schön 1983), with reflection considered important with respect to enabling constructive and appropriate improvement. Research has shown that reflection can be provoked not only through reflecting on action but also when practitioners begin to consider how their experiences are influenced by the physical environment. For example, in a study of carpet space use within a school (McCarter and Woolner 2011) one striking finding was how quite simple feedback from pupils about their experience of this classroom space provoked a teacher to reconsider her practice. She made alterations both to her way of using the space, but also to certain physical elements, such as replacing her chair with a low stool. In considering this study together with other work which involved consulting school users about their premises (Woolner et al. 2012b), we therefore propose that the physical environment is a good place to begin reflection on existing practice, as this is a visible and concrete manifestation of taken for granted ideas and ways of doing things.

It seems clear that a consideration of the physical setting can be a useful part of initiating change, sometimes as an instance of small-scale individual reflection (as we have discussed above) but also as an aspect of larger scale, whole school innovation. This might be understood as using an examination of particular structural features of the existing school (the built environment, but also linked structural elements such as school rules, timetabling and curriculum) to either enable individual agency or to begin a process of cultural change within the school. Such a whole school approach was taken by a secondary school we worked with, as they prepared to move into a new building that was specifically designed to facilitate an interdisciplinary, enquiry-based approach to learning through provision of flexible spaces for team teaching. We have documented the process of initiating change in detail previously (Woolner et al. 2012a, 2014).

Although we were not directly involved with the school over the next 2 years as they moved into their new building and implemented the planned changes, we followed the story through a series of very critical Ofsted reports. It seems clear that the revolution in educational culture and teacher practices desired by the leadership team and which the new building was meant to support and encourage did not occur. From the Ofsted reports it seems that rather than embedding changed educational practices, the new space was simply making traditional practices more awkward (see Woolner et al. 2014). 
At this stage, it is therefore worth questioning the functionality of initiating change through altering organisational and physical structures, given what is known about change enacted mainly at the structural level. In general, research suggests this is rarely sufficient (Priestley 2011; Gordon and Patterson 2008). For example, Priestley describes relatively superficial structural changes intended to facilitate curriculum innovation but limited by prioritising "externally visible structures rather than addressing underlying practices" and making changes that are "viewed in largely organizational rather than pedagogic terms" (Priestley 2011, p. 13). Similarly, Szczesiul and Huizenga criticize two schools they studied that "created structures... [to support the desired change in teacher behaviour]...but failed to create a cultural context that would bolster teacher efficacy and motivation" (2014, p. 184).

Our contention is that through using the important structure of the physical setting in a careful manner as part of a bigger process, change can be initiated that goes beyond mere structure. The failed attempt at change in the secondary school we worked with can be understood in terms of the school ending up with only an isolated structural change, their new building, without complementary change within school culture and individual action. Notably, a number of staff exercised agency by leaving the school to get jobs in schools with a more traditional, contentled approach. To develop our contention, we now turn to a more detailed discussion of two examples of schools where change was attempted much more successfully. Our analysis of their progression through later phases of change processes, towards Fullan's 'institutionalisation', will enable us to develop this argument as well as reflecting on what this interpretation might mean for more general understandings of the concept of 'structure'.

\section{Two examples of change}

\section{Open Futures at Southside School}

Southside Primary School educates children aged 4-11 years with predominantly two classes per year group (420 pupils on roll in 2013-2014). It is located in a city in the north east of England that has seen a trend of de-industrialisation and rising unemployment over the last decades. The ward served by the school is in the top 5\% most deprived areas of the UK, as is the wider city, and generally around half the students are eligible for Free School Meals (FSM). Pupil Mobility is around 23\%, which is above both local authority (LA) and national averages and in the past 6-7 years the school has experienced a dramatic increase in the number of pupils for whom English is an Additional Language (EAL), with 23 languages now spoken in school and EAL pupils comprising around $18 \%$ of the total.

In September 2011, Southside began 2 years of initial training and development as part of the Open Futures programme. Open Futures is a skills and enquiry based learning programme (http://www.openfutures.info/index.htm) for primary schools, which intends to facilitate change in pedagogy and curriculum. There are four integrated strands: growit; cookit; filmit; and askit (Philosophy for Children). The 
school had previous gardening experience, but had little or no history of using the other strands as vehicles for learning. In deciding to get involved with Open Futures, Southside committed itself to the 2 years of supported development, which included making a financial contribution to the costs of training. The additional commitment of staff time and inclusion within school planning came under some pressure when Southside was inspected in September 2012 by the UK's Ofsted service and it was judged that the school 'requires improvement'.

The head teacher, however, was excited by Open Futures as a means through which the school could widen their curriculum, providing a range of new and engaging experiences for pupils. It was hoped that, in time, this would result in increases in attainment, as required by Ofsted, and the development of independent learning skills that could be applied across the curriculum and beyond.

\section{Supporting change}

In common with the other schools involved in the programme, Open Futures at Southside acted as a catalyst for immediate tangible changes that the school was intending or aspiring to make in curriculum content, development of physical space, enterprise and community links. This was seen in the finding and organising of physical space for the programme, new topics added to the curriculum to build links between strands and with existing content, and open days to showcase gardening and involve parents. Strand leads were appointed for each strand. The head teacher also ensured that Open Futures was on the agenda for school and governors meetings, and adapted budgets and staff deployment to accommodate and resource the programme.

Growing areas were extended and developed throughout the school grounds, enabling easy access for all classes and planting in tyres and pots to maximise the use of space and ensure high visibility. Southside developed an existing mobile classroom into a cooking space with adjoining classroom, and space was found for filmit, in a classroom now to devoted to filmit and music, allowing easy access to resources and additional space for activities (see Fig. 1).

Southside staff got involved in the programme as a school initiative. There was some pre-existing knowledge among staff members but this was diverse and not integrated. Although some had prior experience or skills in a particular strand, many did not and were reliant on the Open Futures training to up-skill themselves as well as learning specific teaching techniques relevant to the strands.

Both pupils and staff were enthusiastic about Open Futures. Pupils commented that they value learning new skills that they can then use at home and in the future, as well as appreciating the strands as 'fun', 'exciting', 'different' and 'messy'. In terms of enjoyment, pupils rated cookit and filmit particularly highly. Staff believed that this enjoyment is significant in engaging children in learning and reported that behaviour is particularly good during Open Futures sessions. As anticipated, the Open Futures activities provided a context for other learning:

What we do know is that it tends to be the Open Futures things that children remember having done you know, so if you say to them you know we were 


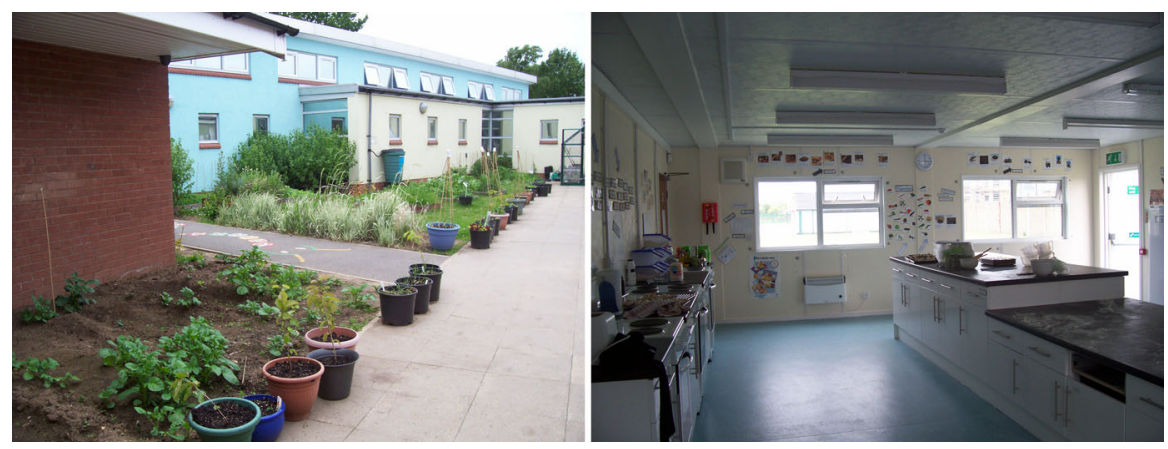

Fig. 1 Space developed to accommodate new activities includes accessible, visible growing areas (left) and an existing mobile classroom developed into a cooking space (right)

talking about gasses and you say to them remember when we did that and it's the yeast activity in the cookery room they tend to remember (head teacher).

Initially, explicit links were built between strands, curriculum topics and skills. Exemplifying this approach is a questionnaire comment, made in spring of the second year of the programme, by a Southside teacher explaining that $\mathrm{s} / \mathrm{he}$ was involved in the following curriculum development:

Plan strands into the yr 2 curriculum. Try to fit NC \& OF into a timetable.

Each term we try to incorporate each strand into the topic.

Over time however, the links between the elements of Open Future and with the wider school curriculum became more seamless, although there were still recognisable Open Futures activities, often taking place in the explicitly Open Futures spaces as described above.

\section{Sustaining change}

After two school years involved in the Open Futures programme a number of changes had occurred at Southside. The integration and mutual dependence of these developments, together with the evident enthusiasm of the head teacher and other staff, suggested to us that these were indeed signs of deeply embedded change in pedagogy and culture.

When school level test results showed small, but positive, change the head was cautious, proposing that there could be a link between raised attainment and the programme. She was further convinced of the efficacy of Open Futures because, as she pointed out, implementing such a programme may in the short term put outcomes under pressure:

...for attendance to make slight gains and for attainment as measured in SATs etc. to hold steady at a time of curriculum change, i.e. the implementation of O.F strands, is in itself noteworthy because change which involves everyone learning new skills and finding ways to include them across the curriculum could have been a disruption that caused a dip in these measures until it 
became embedded in practice. I think that it is a tribute to the quality of the training and to the staff of all the schools that this did not happen. (Head teacher, email, 27.1.14)

This suggests change within practices and understanding at Southside, but it is evident that these more intangible developments are bolstered by embedded changes to curriculum, staff training and the school environment. For example, training of Southside staff in askit ensured that this strand had become an integral part of learning from Foundation Stage through to Year 6. Yet the development of askit was also supported by the physical environment, since, in addition to exploring topics in lessons, pupils were encouraged to use the 'wonder tree' (see Fig. 2) as a means to ask questions and offer answers across the school. This proved to be a popular resource, facilitating reflections and conversations across year groups.

\section{Achieving ‘institutionalisation'?}

It is worth reviewing how this change occurred. We observed initial physical alterations and organisational changes becoming established, being further

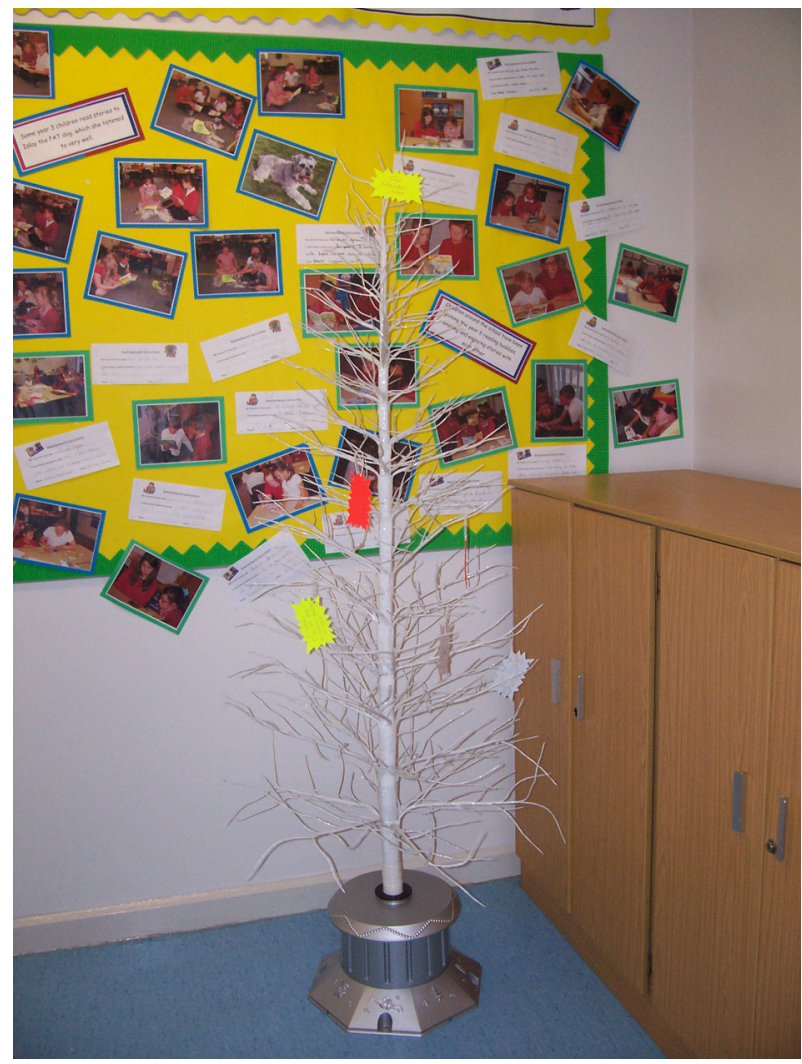

Fig. 2 The 'wonder tree' supports questioning between pupils of different ages 
developed, and helping to embed Open Futures activities in the life of the school. Over time, Open Futures became less explicitly referenced in school planning, because it was so accepted. It was firmly rooted in the school's use of space, within specialist areas and in general classrooms. It was also bolstered through protected budgets and established staffing. During the later interview and in subsequent email communication, the Southside head teacher described how the changes due to the programme enabled better learning processes and teaching practices to continue to develop.

Staff professional development through Open Futures enabled teachers at Southside and the other schools to make the strands and activities their own. Open Futures tends to embed collaborative practices between staff members, enhancing curriculum coherence and pastoral care across the school. As seen at Southside, once Open Futures is established, there is on-going, mutually dependent development of curriculum, organisation and space. In this and other ways, Open Futures strands are integrated with the wider curriculum and this integration is embedded in physical space, particular activities and ways of learning.

It may at first appear that innovation through Open Futures was enacted mainly at the structural level, which, as discussed above, is rarely sufficient to bring about real change. However, we would like to argue that, contrary to a cursory view, detailed examination of the change process at Southside, and other Open Futures schools, reveals changes at the levels of individual agency and culture, in addition to the many structural changes described above. The Open Futures support and community provides a culture within which school staff can situate and understand the structural changes. The distinctiveness of this culture from the prevailing culture in English education appears to enhance the agency of school leaders, as demonstrated by the Southside head teacher. Meanwhile, the practical development of the programme which depends on devolving responsibility to staff, tends to enable individual agency thus allowing staff to make progress with their part of the programme. This can be seen, for example, through the allocation of strand leadership roles to staff, mainly teachers, and in increased involvement of teaching assistants in developing specific strands.

Table 1 summarises the changes we saw at the early and later stages of implementation, supporting and then sustaining the intended change, together with the suggestions of institutionalisation that were becoming evident:

Open Futures at Southside School has provided us with an example of innovation which was extremely successful as a result of change at a structural, cultural and individual level. In order to explore this idea further we now turn to a school where a longer term change process within a considerably bigger institution demonstrates interesting but perhaps more mixed results.

\section{Building learning power and project-based learning at Town End Academy}

Town End Academy is a larger than average secondary school in the north east of England. The school operates on two sites, one of which houses the Key Stage 3 pupils (aged 11-14) and the other the Key Stage 4 pupils and sixth form (aged 14-18). Many of the teachers travel between both schools over the course of a 
Table 1 Changes at Southside

\begin{tabular}{|c|c|c|c|}
\hline & \multicolumn{3}{|l|}{ Stages of change } \\
\hline & Supporting & Sustaining & Institutionalisation \\
\hline \multicolumn{4}{|c|}{ Location of change } \\
\hline Individual & $\begin{array}{l}\text { Head teacher's } \\
\text { hopes } \\
\text { Staff enjoy initial } \\
\text { training }\end{array}$ & $\begin{array}{l}\text { Strand leaders have some autonomy } \\
\text { Class teachers enact strands, using } \\
\text { classroom space and creating } \\
\text { displays }\end{array}$ & $\begin{array}{l}\text { Teachers can plan for more } \\
\text { engaged, better skilled } \\
\text { learners }\end{array}$ \\
\hline Structural & $\begin{array}{l}\text { Initial training, } \\
\text { planning and } \\
\text { organising } \\
\text { Strands linked to } \\
\text { existing } \\
\text { curriculum } \\
\text { New curriculum } \\
\text { content } \\
\text { Specific spaces } \\
\text { found } \\
\text { Timetabling } \\
\text { Staffing } \\
\text { Events with parents }\end{array}$ & $\begin{array}{l}\text { Askit training for all staff } \\
\text { Corridor displays, 'Wonder Tree' } \\
\text { Growing spaces continue to be } \\
\text { developed } \\
\text { Curriculum links developed } \\
\text { Enhances staff collaboration }\end{array}$ & $\begin{array}{l}\text { Need to maintain skills } \\
\text { through CPD } \\
\text { Specialist space as part of } \\
\text { school facilities }\end{array}$ \\
\hline Cultural & $\begin{array}{l}\text { Open Futures } \\
\text { offers alternative } \\
\text { values }\end{array}$ & $\begin{array}{l}\text { Increased parental attendance at } \\
\text { events } \\
\text { Staff and students valuing different } \\
\text { sorts of learning }\end{array}$ & Children thinking differently \\
\hline
\end{tabular}

school week. The school has a below average number of pupils of an ethnic minority, on free school meals or with special educational needs.

In 2006 the school began experimenting with enquiry-based learning in order to provide the students with an engaging curriculum that would also connect them to their local area. The initial impetus for this experimentation came from the deputy head teacher who felt that the poor behaviour being exhibited by many of the pupils was the result of emotional immaturity and a lack of interest in learning. Her decision to research a range of curricula coincided with radical changes to the Key Stage 3 curriculum introduced by the UK government. This included the abolition of the end of Key Stage 3 national test and a renewed focus on creativity.

The deputy head was determined to develop a sustainable vision for the school and to that end she set up a working group which any members of staff could join. Seventeen took part, representing every faculty and a range of teaching experience. The group started with an initial research question: What kind of children do we want and how do we get this? The staff visited schools around the country that were putting a variety of different approaches into practice and finally settled on the Building Learning Power (BLP) programme developed by Guy Claxton. This focuses on 'creating a culture in classrooms - and in the school more widely-that 
systematically cultivates habits and attitudes that enable young people to face difficulty and uncertainty calmly, confidently and creatively' (http://www. buildinglearningpower.co.uk/). The school created their own cross- curricular programme (history, geography, RE, design and technology and art) which they called 'Inspiring Minds' and which consists of 9 hours of curriculum time. This introduces the pupils to the habits of mind, collaborative working, research, reflection and the language of learning.

\section{Supporting change}

In order to create a workable model for introducing the Inspiring Minds programme, it was initially introduced to the Year 7 pupils in 2006/7. Then in 2008/9 the key principles which underpin the programme were incorporated into the lessons of the remaining year groups, including the sixth form. All of the teachers are expected to plan and teach the content of their subjects in ways that reflect the values and skills that the programme promotes.

As well as the changes made to the curriculum and the timetable, the senior leadership team also encouraged the teachers to rearrange the furniture in the classrooms so that collaboration between the pupils would be facilitated. Circular tables were purchased for some classrooms and in others the teachers created $\mathrm{L}$ or $\mathrm{U}$ shapes or grouped two tables together. Pupils were expected to sit facing one another so that they learn from each other as well as the teachers.

\section{Sustaining change}

The head teacher and senior leadership team all promote the ethos of the school and the BLP programme and the teachers are supported to both understand and deliver the approach through a comprehensive structured programme of CPD which includes residentials and coaching. Sharing good practice is also encouraged through the creation of an open-door policy whereby teachers can observe one another's teaching. Promotion structures have also been linked to the ability of teachers to model good learning and enact the principles of BLP. Notably, the arrangement of classroom furniture has continued to be used to both facilitate and promote the collaborative learning that is desired. Tables in rows are not allowed and the classrooms are monitored to ensure that such rearrangement does not occur. The rationale for this is that tables in rows would represent a teacher who does not embody the values and vision of the school.

In 2013 the school started working with staff from High-Tech High in San Diego, USA and the Innovation Unit to introduce and develop Project-Based Learning. With its focus on cross-curricular projects that promote reflection, critique and producing high-quality work for an audience that includes the community, projectbased learning seemed a natural step for the school to take and one that fitted in with the programme already in place. The staff embraced the principles of PBL, including the concept of collaborative planning which the High Tech High teachers introduced (e.g. project tuning). A series of projects was developed, including both cross-curricular and within subject projects, in every year group. However the 
development of project-based learning has suffered a series of setbacks recently. The reasons for this include: the departure of a key member of staff with responsibility for its development within the school, the introduction of the new secondary curriculum which requires more time for teaching subject content and finally aspects of the physical school space which are not conducive of project based learning.

Although the school premises include large rooms that can accommodate end of project exhibitions (see, e.g. Fig. 3), the classrooms and split site do not make the development stages of projects easy. Teachers in the school do not have their own classrooms, but instead teach in four to five rooms, often across the two school sites. As a consequence they do not have ownership over the teaching spaces and cannot create the type of areas needed to allow the pupils to work independently on a variety of activities (i.e. areas for research, computer areas, craft areas). Collaboration between the staff is also impeded by the fact that each subject area has its own office (i.e. a Maths Department office, an English Department office) and this is where the teachers do their planning and spend most of their breaks and lunchtimes. This limits the practice of cross-curricular team work, reducing chance interactions as well as making deliberate collaboration more difficult to arrange.

\section{Achieving 'institutionalisation'}

However, having experienced the increased engagement of the pupils who take part in project-based learning as well as the improved quality of their work, the senior leadership team are determined to put structures in place that will enable the staff to feel confident to teach projects at key points in the year. This process has begun with the creation of a weekly programme of CPD that will address the key issues and stages: critique, project tuning, planning a project. Crucially the programme will involve teachers from partner schools who are also developing this approach. This will encourage the sharing of good practice and provide a space, organisationally and physically, to discuss the challenges being faced.

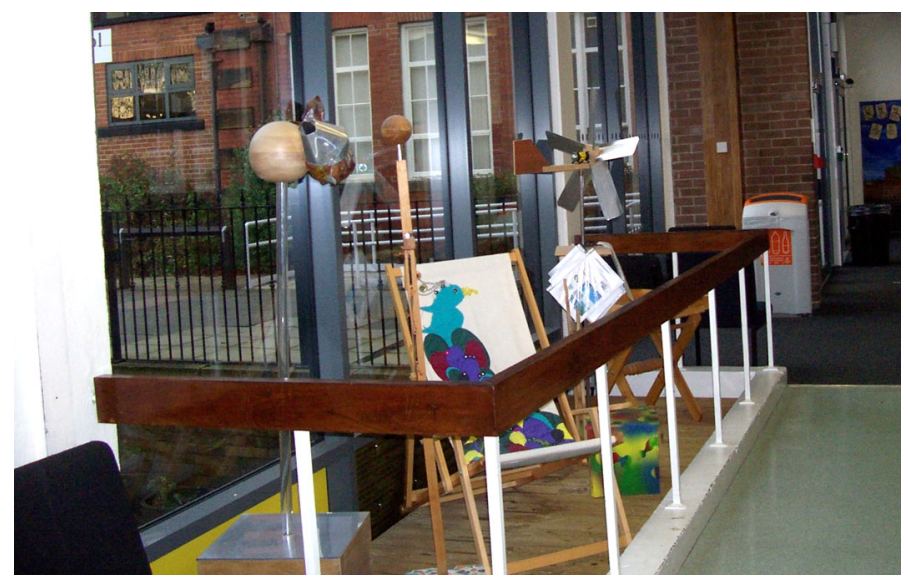

Fig. 3 Space to display the results of projects 
The changes at Town End are summarised in Table 2 as for Southside:

Although not an initial driver of the changes the school has made, the physical environment has facilitated and supported the changes in classroom and curricular practices achieved over the last decade. However, it would appear that aspects of school space are hindering further development. In particular, subject specific offices are making cross-curricular planning more difficult and causing other contact between subject teachers to be infrequent. It could be argued that this physical limitation is impacting on further structural developments, such as curriculum developments, but also affecting development of an appropriate culture of education at Town End. In addition, the issues around classroom arrangement and the lack of ownership can be interpreted as hindering the agency of individual teachers to develop the project based approach. Considered in this way, we suggest that, while the changes have been successful so far, a failure to engage with these current challenges could result in pedagogical innovation at Town End existing only at the structural level (curriculum and tables), which makes it vulnerable.

\section{School change: Where does the physical environment fit?}

As has been discussed, and demonstrated using our detailed examples, change in schools $i s$ linked to the physical environment. The existing school space can either support or constrain the achievement of desired change, with investigation of the

Table 2 Changes at Town End

\begin{tabular}{|c|c|c|c|}
\hline & \multicolumn{3}{|l|}{ Stages of change } \\
\hline & Supporting & Sustaining & Institutionalisation \\
\hline \multicolumn{4}{|c|}{ Location of change } \\
\hline Individual & $\begin{array}{l}\text { Teachers could join } \\
\text { initial working group }\end{array}$ & $\begin{array}{l}\text { Teachers developing projects } \\
\text { Cross-curricular work } \\
\text { encouraged }\end{array}$ & $\begin{array}{l}\text { Some teachers see } \\
\text { themselves as facilitators } \\
\text { of learning }\end{array}$ \\
\hline Structural & $\begin{array}{l}\text { Used BLP to develop } \\
\text { cross-curricular } \\
\text { 'Inspiring Minds' } \\
\text { programme } \\
\text { Habits of mind } \\
\text { incorporated into } \\
\text { other teaching } \\
\text { Furniture to support } \\
\text { student collaboration }\end{array}$ & $\begin{array}{l}\text { Comprehensive CPD } \\
\text { No rows of tables; Link to High } \\
\text { Tech High } \\
\text { Large spaces used for project } \\
\text { exhibitions (space for project } \\
\text { development hard to find) } \\
\text { Departmental offices enhance } \\
\text { within subject collaboration } \\
\text { (but limit cross-curricular } \\
\text { planning) }\end{array}$ & $\begin{array}{l}\text { CPD with partner school } \\
\text { 'Inspiring Minds' } \\
\text { programme embedded in } \\
\text { school curriculum and } \\
\text { timetable }\end{array}$ \\
\hline Cultural & $\begin{array}{l}\text { BLP offers an } \\
\text { alternative } \\
\text { understanding of } \\
\text { learning }\end{array}$ & $\begin{array}{l}\text { Staff to support school values } \\
\text { Student engagement with projects }\end{array}$ & \\
\hline
\end{tabular}


school community's use and views of the premises helpful at the initiation stage. As well as revealing where challenges lie, we have argued that the physical space offers a usefully visible and tangible focus for reflection on existing practices and the collaborative development of ideas for change. The school examples demonstrate how, within a change process that includes the physical setting, changes to school space can support both initial innovation and sometimes further development of a new approach, helping to institutionalise the change. As noted in the introductory sections of this paper, this influence of the physical setting on the process and outcomes of school change is suggested by some researchers in educational change and policy enactment, but rarely examined thoroughly. However, the history of school design has demonstrated that such alterations of physical space do not always result in wider change in school culture and in the practices of individuals. The question is whether our examples, explored through Priestley's framework, can help us to understand the reasons for such unevenness of success.

Much research has shown that change in school that is merely structural is rarely sustained. Thus the alteration of school space alone, as often occurred during the 1960s and 70s when open plan schools were built, would not be expected to succeed. In the schools we have researched, the school leaders initiating change showed awareness of this complexity: they often spoke explicitly about the need to change teaching or learning culture, and seemed to see the changed space as part of an integrated pedagogical, cultural and organisational whole. We have argued, however, that they were not all equally successful in realising this vision. Considering the process of change using Priestley's framework has enabled us to understand and explain the success of Open Futures at Southside and the on-going challenges of pedagogical innovation at Town End.

Our extra contribution to the debate in this area is to argue that change to the physical setting, understood as part of the whole that is the school learning environment, can be particularly powerful. Where the change extends to school culture and facilitates non-conflicting individual agency, then the physical environment appears to be key within structural changes. Within the change enacted through Open Futures at Southside, the centrality of the physical environment through the stages of development is notable. As described above, the programme has some clear initial requirements for physical changes to be made, most specifically for the growit and cookit strands. Similarly, at Town End, the early innovations were seen to centre on student collaboration, necessitating particular types and arrangements of furniture. Once in place the specialist Open Futures spaces facilitated early curricular and pedagogic change, but also enabled progress towards further integration within the strands and with the existing curriculum. The spatial and physical innovations therefore strengthen the structural change, but also enable and support teacher agency in ways reminiscent of Priestley's observations of successful curriculum change. Spaces exist within and beyond the classroom that encourage individual teachers to try the new ways of working and support them to develop certain aspects of their practice. Kitchens and garden areas, but also strand spaces such as displays, were observed to achieve this function for Open Futures. At Town End, the provision of circular tables and arrangement of classroom furniture facilitated the development by teachers of collaborative learning approaches. In 
addition, these spaces provide a tangible reminder of new intentions and values contributing to a change in school culture: in finding classroom space for filmit, the Southside head signalled her belief in this as valuable learning as well as providing a base for the strand. At Town End, tables in rows were seen as undermining the values and ethos of the school. Thus the physical space, which could be seen as the most obvious of school structures, is the key to moving beyond mere structural change because the physical learning environment is uniquely visible and tangible-a manifestation of a school's values and the teachers' pedagogic approaches, providing possibilities for further individual action. Instead of school staff being trapped by "the institutionalized definitions of learning embodied in the physical environments in which they work" (Elmore 2016, p. 536), engaging with and changing space may enable "teachers to turn to material objects in full knowledge of the pedagogic possibilities they open up" (Mulcahy et al. 2015, p. 590).

\section{School structures: What does this reveal about the concept?}

The understanding we have developed of change in schools and, specifically, our analysis of the stages and process of change in the examples presented, builds on the approach developed by Priestley and colleagues. We would concur with them on the value of attempting to disentangle culture, structure and individual action, even though the analysis demonstrates their interdependence. In our two examples, it becomes evident how the cultural and structural changes first support, and then come to be sustained by, the individual actions of teachers and students. Teachers have agency within this system, but it is of a particular type. This can be understood as producing the collective endeavour that Ouston and colleagues discovered some decades ago in schools successfully navigating change, at the time noting that this meant that "teachers may have less professional autonomy than would be the case elsewhere" (Ouston et al. 1991, p. 10).

Our conceptualisation, however, includes noting the particular contribution of the physical setting in enacting, sustaining and embedding change. We believe that this is an important refinement of the culture, structure and agency framework, justified by the additional understanding produced and the potential for awareness of the physical setting to be of use to researchers and practitioners alike. It is worth questioning, however, whether this refinement, which we see as more fundamental than a change in emphasis, has implications for how structure is understood, firstly within the school context, but also more generally.

As noted, sociologists tend, when investigating the potential for individual action, to emphasise the social structures through which society is organised as opposed to the related material and physical structuring that also impacts on individuals. Even when a classic sociology text explicitly considers the built environment of school (Meighan et al. 2007: 91-104), this is in the context of a section on the 'hidden curriculum' and centres on the symbolic as opposed to the pragmatic (see Proshansky and Wolfe 1974 for discussion of this distinction) constraints and affordances of school space. Thus the rather dated references are used to argue that spaces "may be indicative of assumptions about relationships" (p. 
95) and that both schools and classrooms "imply psychological, philosophical, sociological and pedagogical assumptions" (pp. 92 and 97), but there is less analysis of how this works in practice, with the emphasis on the messages conveyed rather than how this is achieved. It seems possible that working in this sociological tradition has led Maguire and colleagues to focus on the social aspects of "the different positions and perspectives of the local actors" (Maguire et al. 2015, p. 496), although, as we have noted, they are not unaware of the physical side.

Similarly, Archer in her theorising about individual actions centres her discussion on how individuals may develop agency within the cultural and social structures that surround them. Although Archer is clear that the social structures have material elements, such as economic circumstances and geographical location, her emphasis remains on social understandings of these aspects, which perhaps is inevitable for these more complex material considerations. Within the smaller environment of a school, the sorts of material aspects we have been noticing are considerably more tangible than economic status, so perhaps it is not surprising that we are proposing that they be considered differently.

A possible solution to the issue of giving appropriate acknowledgement to the contribution of the physical environment is provided by Priestley's more recent discussion of how individual agency is achieved in settings that can be understood as providing the actor with "cultural, material and structural resources" (Biesta et al. 2015: 627). Although this draws suitable attention to school space and equipment, we feel that the distinction made between structural and material elements is likely to drift into an unhelpful dichotomy between the social and the physical. Our examples include elements found to be important to the change processes that would be difficult to classify as material or social structures, such as timetables and curricular documents. Such a theoretic move also seems counter to the work previously noted that has emphasised the essentially social side to school environments, and makes it hard to understand the power of the apparently simple physical objects we encountered, such as the 'Wonder Tree', to change practice. Considering social and material structures as intimately interlinked also coheres with the overlapping of organisational, social and material aspects of the learning environment proposed by Gislason, the articulation of learning space as created by "a range of dynamics...discursive, material and social" (Mulcahy et al. 2015, p. 591) and the empirical work of other researchers (e.g. Saltmarsh et al. 2015; McGregor 2003). This inherent entwining is important given that Gislason's work includes seminal findings about the need for these elements to be in coherence rather than conflict for a learning environment to be successful (see Gislason 2015). It is through attending to this alignment of distinct yet interwoven elements that improvements can be made in actual educational settings, recognising that "effecting pedagogical change...is a relational achievement drawing on diverse social, discursive and material resources" (Mulcahy et al. 2015, p. 589, italics in original).

In conclusion, we support the proposition that the framework for analysing school change, developed by Priestley and colleagues, has utility and analytical power. However we believe that our research has identified a need to consider more centrally the physical elements of school structures in any analysis. Whilst acknowledging the way that these are entwined with other structural aspects, 
specifically those that are more social, we do not see how they can be either reduced to social understandings or wholly separated from them. Further research is instead required to investigate within schools how the social and physical aspects of school structures interact with each other and with the cultural assumptions and opportunities for individual agency. Such conceptually-driven investigation will enable scholars to develop further our understanding of successful school change, and so produce theoretically grounded advice for policy and practice.

Open Access This article is distributed under the terms of the Creative Commons Attribution 4.0 International License (http://creativecommons.org/licenses/by/4.0/), which permits unrestricted use, distribution, and reproduction in any medium, provided you give appropriate credit to the original author(s) and the source, provide a link to the Creative Commons license, and indicate if changes were made.

\section{References}

Alterator, S., \& Deed, C. (2013). Teacher adaptation to open learning spaces. Issues in Educational Research, 23(3), 315-330.

Archer, M. (2000). Being human: The problem of agency. Cambridge: Cambridge University Press.

Ball, S. J. (1981). Beachside comprehensive: A case-study of secondary schooling. Cambridge: Cambridge University Press.

Ball, S. J. (1993). What is policy? Texts, trajectories and toolboxes. Discourse: Studies in the Cultural Politics of Education, 13(2), 10-17.

Bennett, N., Andreae, J., Hegarty, P., \& Wade, B. (1980). Open plan schools. Windsor: Schools Council Publishing/NFER.

Biesta, G., Priestley, M., \& Robinson, S. (2015). The role of beliefs in teacher agency. Teachers and Teaching, 21(6), 624-640.

Blackmore, J., Bateman, D., Cloonan, A, Dixon, M., Loughlin, J., O’Mara, J., et al. Innovative learning environments research study. https://www.deakin.edu.au/_data/assets/pdf_file/0003/365196/ innovative-learning-spaces-final-report.pdf Accessed 29 September 16.

Blackmore, J., Bateman, D., Loughlin, J., O’Mara, J., \& Aranda, G. (2011). Research into the connection between built learning spaces and student outcomes. Melbourne: Education Policy and Research Division, Department of Education and Early Childhood Development.

Boys, J. (2011). Towards creative learning spaces: Re-thinking the architecture of post-compulsory education. Abingdon: Routledge.

Briggs, A. (2001). Managing the learning environment. In D. Middlewood \& N. Burton (Eds.), Managing the curriculum. London: Sage.

Campbell, M., Saltmarsh, S., Chapman, A., \& Drew, C. (2013). Issues of teacher professional learning within 'non-traditional' classroom environments. Improving Schools, 16(3), 209-222.

Cleveland, B., \& Fisher, K. (2014). The evaluation of physical learning environments: A critical review of the literature. Learning Environments Research, 13(1), 1-28.

Dovey, K., \& Fisher, K. (2014). Designing for adaptation: The school as socio-spatial assemblage. The Journal of Architecture, 19(1), 43-63.

Elmore, R. F. (2016). "Getting to scale..." it seemed like a good idea at the time. Journal of Educational Change, 17(4), 529-537.

Frelin, A., \& Grannäs, J. (2014). Studying relational spaces in secondary school: Applying a spatial framework for the study of borderlands and relational work in school improvement processes. Improving Schools, 17(2), 135-147.

Fullan, M. (2007). The new meaning of educational change (4th ed.). New York/Abingdon: Routledge.

Gislason, N. (2010). Architectural design and the learning environment: A framework for school design research. Learning Environments Research, 13, 127-145.

Gislason, N. (2015). The open plan high school: Educational motivations and challenges. In P. Woolner (Ed.), School design together. Abingdon: Routledge.

Gordon, J., \& Patterson, J. A. (2008). It's what we've always been doing. Exploring tensions between school culture and change. Journal of Educational Change, 9(1), 17-35. 
Hargreaves, A. (2002). Sustainability of educational change: The role of social geographies. Journal of Educational Change, 3, 189-214.

Horne, S. C. (1999). Classroom environment and its effects on the practice of teachers. Ph.D. thesis, University of London.

Horne-Martin, S. (2002). The classroom environment and its effects on the practice of teachers. Journal of Environmental Psychology, 22(1-2), 139-156.

Imms, W., \& Byers, T. (2017). Impact of classroom design on teacher pedagogy and student engagement and performance in mathematics. Learning Environments Research, 20, 139-152.

Leat, D., \& Thomas, U. (2017). Community curriculum making and EPBL. In D. Leat (Ed.), Enquiry and project based learning: Students, schools and society. Abingdon: Routledge.

Maguire, M., Braun, A., \& Ball, S. (2015). 'Where you stand depends on where you sit': The social construction of policy enactments in the (English) secondary school. Discourse: Studies in the Cultural Politics of Education, 36(4), 485-499.

Massey, D. (2005). For space. London: Sage.

McCarter, S., \& Woolner, P. (2011). How listening to student voice can enable teachers to reflect on and adjust their use of physical space. Educational and Child Psychology, 28(1), 20-32.

McGregor, J. (2003). Making spaces: Teacher workplace topologies. Pedagogy, Culture and Society, 11(3), 353-376.

McGregor, J. (2004a). Editorial. FORUM, 46(1), 2-5.

McGregor, J. (2004b). Spatiality and the place of the material in schools. Pedagogy, Culture and Society, 12(3), 347-372.

Meighan, R., Harber, C., Barton, L., Siraj, I., \& Walker, S. (2007). A sociology of educating (5th ed.). London/New York: Continuum.

Mulcahy, D., Cleveland, B., \& Aberton, H. (2015). Learning spaces and pedagogic change: Envisioned, enacted and experienced. Pedagogy, Culture \& Society, 3(4), 575-595.

Nespor, J. (2002). Studying the spatialities of schooling [Essay Review]. Pedagogy, Culture and Society, 10(3), 483-492.

Ouston, J., Maughan, B., \& Rutter, M. (1991). Can schools change? II: Practice in six London secondary schools. School Effectiveness and School Improvement, 2(1), 3-13.

Pollard, A. (1985). The social world of the primary school. London: Holt, Rinehart and Winston.

Priestley, M. (2011). Schools, teachers, and curriculum change: A balancing act? Journal of Educational Change, 12, 1-23.

Priestley, M., Millera, K., Barrettb, L., \& Wallacec, C. (2011). Teacher learning communities and educational change in Scotland: The Highland experience. British Educational Research Journal, $37(2), 265-284$.

Proshansky, E., \& Wolfe, M. (1974). The physical setting and open education. The School Review, 82(4), 556-574.

Saltmarsh, S., Chapman, A., Campbell, M., \& Drew, C. (2015). Putting "structure within the space": Spatially un/responsive pedagogic practices in open-plan learning environments. Educational Review, 67(3), 315-327.

Schön, D. A. (1983). The reflective practitioner: How professionals think in action. London: Temple Smith.

Sigurðardóttir, A. K., \& Hjartarson, T. (2011). School buildings for the 21st century. Some features of new school buildings in Iceland. CEPS Journal, 1(2), 25-43.

Szczesiul, S., \& Huizenga, J. (2014). The burden of leadership: Exploring the principal's role in teacher collaboration. Improving Schools, 17(2), 176-191.

Thomson, P. (2007). Whole school change: A review of the literature. London: Arts Council England.

Thomson, P., \& Hall, C. (2016). Place-based methods for researching schools. London: Bloomsbury.

Thomson, P., McGregor, J., Sanders, E., \& Alexiadou, N. (2009). Changing schools: More than a lick of paint and a well-orchestrated performance? Improving Schools, 12(1), 43-57.

Tyack, D., \& Tobin, W. (1994). The 'grammar' of schooling: Why has it been so hard to change? American Educational Research Journal, 31(3), 453-479.

Uline, C. L., Tschannen-Moran, M., \& DeVere Wolsey, T. (2009). The walls still speak: The stories occupants tell. Journal of Educational Administration, 47(3), 400-426.

Weinstein, C. S. (1979). The physical environment of the school: A review of the research. Review of Educational Research, 49(4), 577-610. 
Woolner, P., Clark, J., Laing, K., Thomas, U., \& Tiplady, L. (2012a). Changing spaces: Preparing students and teachers for a new learning environment. Children, Youth and Environments, Special Issue: Reconceptualising School Design: Child and youth environments for learning, 22(1), 52-74.

Woolner, P., Clark, J., Laing, K., Thomas, U., \& Tiplady, L. (2014). A school tries to change: how leaders and teachers understand changes to space and practices in a UK secondary school. Improving Schools, 17(2), 148-162.

Woolner, P., Hall, E., Wall, K., Higgins, S., \& McCaughey, C. (2007). A sound foundation? What we know about the impact of environments on learning and the implications for Building Schools for the Future. Oxford Review of Education, 33(1), 47-70.

Woolner, P., McCarter, S., Wall, K., \& Higgins, S. (2012b). Changed learning through changed space: When can a participatory approach to the learning environment challenge preconceptions and alter practice? Improving Schools, 15, 45-60.

Woolner, P., \& Tiplady, L. (2016). Adapting school premises as part of a complex pedagogical change programme. In U. Stadler-Altmann (Ed.), (English) Learning environment. educational and architectual views on schoolbuildings and classrooms. (German) Lernumgebungen. Erziehungswissenschaftliche und architekturkritische Perspektiven auf Schulgebäude und Klassenzimmer (pp. 69-81). Opladen/Berlin/Toronto: Barbara Budrich. 